\title{
Simulation of Grid-Connected Solar Micro-inverter Based on Fuzzy PI Controller
}

\author{
Weiliang Liu ${ }^{1}$, Changliang $\mathrm{Liu}^{2}$, Huichao Zhang ${ }^{3}$, Yongjun $\mathrm{Lin}^{4}$, Liangyu $\mathrm{Ma}^{5}$ \\ State Key Laboratory of Alternate Electrical Power System with Renewable Energy \\ Sources \\ $\left\{{ }^{1}\right.$ lwlfengzhiying, ${ }^{2}$ changliang $l i u,{ }^{5}$ mlydw\} @ 163.com, ${ }^{3} 470848280 @ q q . c o m$, \\ ${ }^{4} l i n 3172 @ 126 . c o m$
}

\begin{abstract}
Grid-connected solar micro-inverter is a highly nonlinear and time-varying system, so it is difficult to achieve good control effect using traditional PI controller. In this paper, small signal analysis model of micro-inverter is established, grid-connected current control strategy composed of fuzzy PI controller and grid voltage feed-forward is put forward, and the initial parameters of PI controller is optimized using the genetic algorithm. Simulation results show that the control strategy has the virtues of good robustness, small dynamic deviation, and could reduce the harmonic content of grid-connected current.
\end{abstract}

Keywords: Micro-inverter ; PI Controller ; Fuzzy Control ; Feed-forward Control ; Genetic Algorithm

\section{Introduction}

With the rapid growth of the world energy demand and gradually reduction of fossil energy, solar power generation system has been widely used in recent years. In the existing photovoltaic power generation system, several PV modules are usually connected in seriesparallel for the sake of getting higher voltage and power levels, and then output power through a larger capacity inverter. However, it is difficult to ensure that they are all working at the maximum power point due to the characteristic difference among PV modules, which causes power loss. If one cell of the solar power generation system is faulty or in shading, it would influence the normal work of the whole system, even causing the interruption of power supply.

In recent years, scholars have put forward the concept of micro inverter, the function of which is to integrate the micro inverter device and solar panel, so as to realize the maximum power tracking in panel level and support hot-plugging. In addition, users could flexibly extend the system capacity. Because micro-inverter could solve the main problems of larger capacity inverter, it becomes the research focus in the current [3-5].

Micro-inverter usually adopts fly-back topology structure, the existing research work is focused on how to perform power decoupling control, as for the grid-connected current control, simple PI controller is usually utilized [6,7,8,9]. The micro-inverter is a highly nonlinear and time-varying system, of which the output power is affected by working conditions of solar panels, and working point has a larger range, so it is difficult to achieve good control effect adopting PI controller with fixed parameters. For example, grid-connected current oscillation happens at the zero crossing point [10], different harmonic content would 
disappear under different power state, which is as high as $11.806 \%$ at the $100 \%$ power operation condition [11].

In this paper, small signal analysis model of micro-inverter is established, gridconnected current control strategy composed of fuzzy PI controller and grid voltage feedforward is put forward, and the initial parameters of PI controller are optimized using the genetic algorithm. Simulation results show that the control strategy has the virtues of good robustness, small dynamic deviation, and could reduce the harmonic content of gridconnected current.

\section{Topology Structure of Micro-inverter}

The topology structure of grid-connected micro-inverter referenced in this paper is shown in Fig. 1. It mainly includes three parts, the DC/DC converter using flyback topology,the DC/AC converter using MOSFET full-bridge, and the EMI filter. Functionally, the DC/DC part can achieve boost transformation, maximum power point tracking (MPPT), and it converts the DC output of the solar panels to a half-wave sinusoidal current. The output halfwave sinusoidal current is converted to be full-wave sinusoidal current by the DC/AC part, and then the current is fed to the EMI filter before the grid.

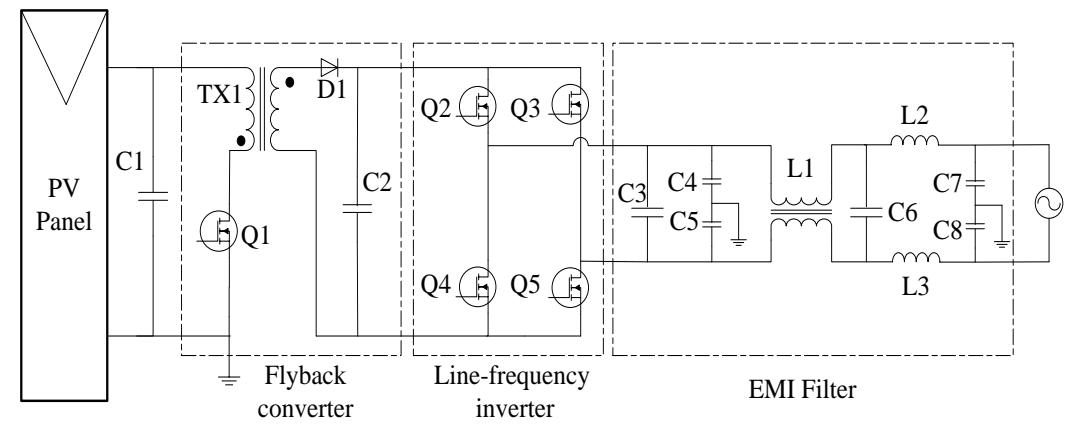

Figure 1 Topology Structure of Grid-connected Micro-inverter

\section{Model of Grid-connected Micro-inverter}

Flyback converter is the core part of the micro-inverter, and its equivalent non-isolated circuit is a Buck-Boost converter, which is essentially a highly nonlinear system [12]. In order to facilitate analysis, the grid voltage $V_{\text {grid }}$ is equivalent to half sine wave, and the system equivalent circuit is shown in Figure 2.

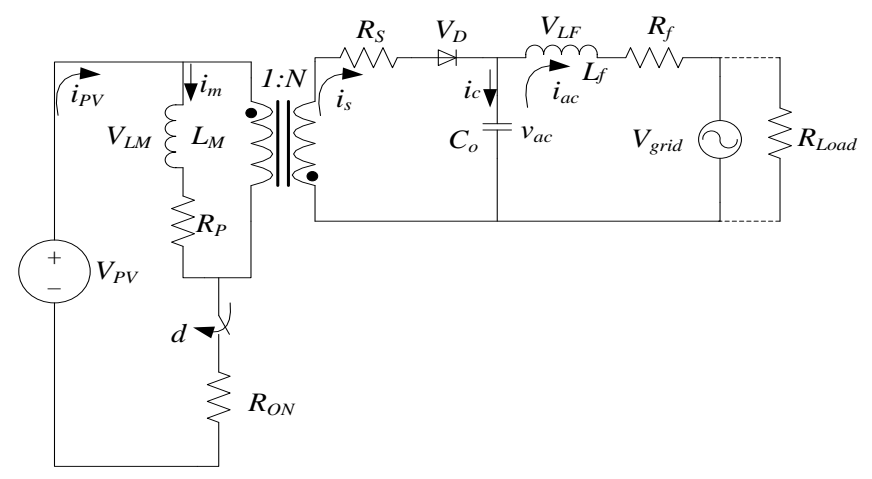

Figure 2 Equivalent circuit of Micro-inverter 
Flyback converter has the following three states that need to be analyzed corresponding to three energy storage elements: flyback inductor current $I_{m}$, flyback output capacitor voltage $V_{a c}$, System output current $I_{a c}$. The averaged Kirchhoff's Voltage Law and Current Law (KVL and KCL) equations of the converter over one switching cycle are shown in Equation (1-6).

$$
\begin{gathered}
V_{L M}=L_{M} \frac{d\left(i_{m}\right)}{d(t)}=d \cdot V_{p v}-d \cdot i_{m}\left(R_{O N}+R_{P}\right)-d^{\prime}\left(\frac{v_{a c}+i_{s} \cdot R_{s}}{N}\right) \\
i_{s}=\frac{i_{m}}{N} \cdot d^{\prime} \\
V_{L F}=L_{f} \cdot \frac{d\left(i_{a c}\right)}{d(t)}=v_{a c}-i_{a c} \cdot R_{f}-V_{g r i d} \\
i_{c}=C_{o} \cdot \frac{d\left(v_{a c}\right)}{d(t)}=i_{s}-i_{a c} \\
V_{g r i d}=R_{\text {load }} \cdot i_{a c} \\
i_{p v}=d \cdot i_{m}
\end{gathered}
$$

Where $d$ is the duty cycle of modulation signal, $d^{\prime}$ is the off-time $(1-d), N$ is the turns ratio of flyback transformer. Assume $X, U$ and $Y$ represent the system static working point, $x, u$ and $y$ are the perturbations over the operating point, then there are

$$
\begin{gathered}
x=X+x=\left[\begin{array}{lll}
I_{m} & I_{a c} & V_{a c}
\end{array}\right]+\left[\begin{array}{lll}
\tilde{i}_{m} & \tilde{i}_{a c} & \tilde{v}_{a c}
\end{array}\right] \\
u=U+u=\left[\begin{array}{lll}
D & V_{g r i d} & V_{p v}
\end{array}\right]+\left[\begin{array}{lll}
d & \tilde{v}_{g r i d} & \tilde{v}_{p v}
\end{array}\right] \\
y=Y+y=\left[\begin{array}{l}
I_{a c}
\end{array}\right]+\left[\begin{array}{ll}
\tilde{i}_{a c}
\end{array}\right]
\end{gathered}
$$

Substituting Equations (7-9) into Equations (1-6), the small signal linearized model is obtained, as shown in Equation (10-11).

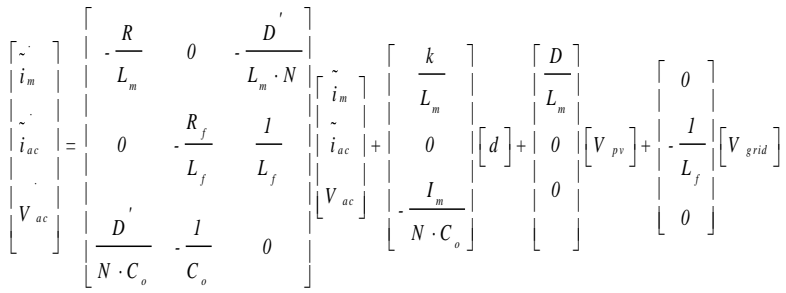

$$
\begin{aligned}
& \tilde{i}_{a c}=\left[\begin{array}{lll}
0 & 1 & 0
\end{array}\right]\left[\begin{array}{ll}
\tilde{i}_{m} & \vdots \\
\tilde{i}_{a c} & \vdots \\
V_{a c}
\end{array}\right]
\end{aligned}
$$

Where

$$
\begin{aligned}
& D^{\prime}=1-D \\
& k=V_{p v}-I_{m}\left(R_{O N}+R_{P}\right)+\frac{v_{a c}+I_{s} \cdot R_{s}}{N} \\
& R=D\left(R_{O N}+R_{P}\right)+\frac{D^{\prime} R_{s}}{N}
\end{aligned}
$$

The transfer function is obtained between the output AC current and modulation input, as shown in Equation (12). 


$$
G(s)=\frac{\frac{k D^{\prime}-I_{m} R}{L_{m} N L_{f} C_{0}} \cdot \frac{I_{m}}{L_{m} C_{0} N} s}{s^{3}+\left(\frac{R}{L_{m}}+\frac{R_{f}}{L_{f}}\right) s^{2}+\left(\frac{R R_{f}}{L_{m} L_{f}}+\frac{1}{L_{f} C_{0}}+\frac{D^{\prime 2}}{N^{2} L_{m} C_{0}}\right) s+\left(\frac{R}{L_{m} L_{f} C_{0}}+\frac{R_{f} D^{2^{2}}}{N^{2} L_{m} C_{o}}\right)}
$$

In this paper, main parameters of grid-connected solar micro inverter are as follows: rated power $P=220 \mathrm{~W}$, flyback transformer turns ratio $N=12, V_{p v}=36 \mathrm{~V}, L_{m}=55 \mathrm{uH}, R_{p}=28 \mathrm{~m} \Omega$, $R_{o n}=15 \mathrm{~m} \Omega, R_{s}=1 \Omega, C_{o}=0.245 \mathrm{uF}, L_{f}=600 \mathrm{uH}, R_{f}=0.61 \Omega$,switching frequency $f=57 \mathrm{KHz}$. Set the effective value of the power grid voltage as $v_{a c}$, namely the $v_{a c}=220 \mathrm{~V}$, then the system Bode plot of the open-loop transfer function is shown in figure 3. From the open-loop Bode plot, it can be observed that both gain margin $\mathrm{Gm}$ and phase margin Pm of the system are quite small, $\mathrm{Gm}=1.65 \mathrm{~dB}, \mathrm{Pm}=7.41^{\circ}$. Thus, the system inherently has a poor relative stability. Additionally, it is also observed that the ripple attenuation at switching frequency $(57 \mathrm{kHz})$ needs improvement and that the system gain at the required operating frequency $(100 \mathrm{~Hz})$ is very low. Therefore, correction to the system must be performed to obtain sufficient stability margin and gain.

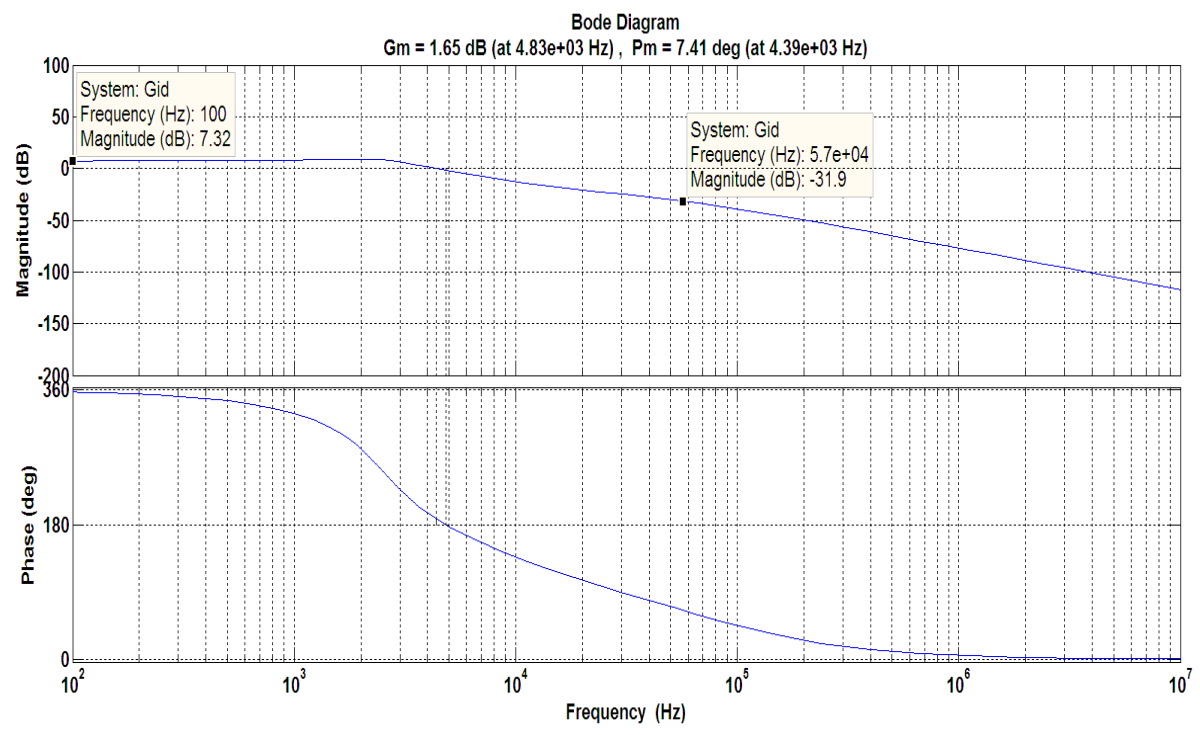

Figure 3 Bode Plot of the Open-loop System

\section{Control Strategy of Grid-connected Current}

Fuzzy control has the virtues of good robustness and strong anti-interference ability, but its performance to reduce the system steady-state error is poor. Fuzzy PI control is the combination of fuzzy control and PI controller, which performs fuzzy reasoning to PI controller parameters proportional coefficient $K_{p}$, integral coefficient $K_{i}$, and makes the system have the characteristics of no steady-state error, good robustness and strong anti-interference ability at the same time $[13,14]$.

The grid-connected current control strategy block diagram composed of fuzzy PI controller and grid voltage feed-forward is shown in Fig. 4. First of all, compare the reference current $i_{a c}{ }^{*}$ with grid-connected instantaneous current $i_{a c}$, calculate the current deviation $E$ and its change rate $E_{c}$ as the input of fuzzy controller, then fuzzy reasoning is performed based on 
the fuzzy rules, and proportional coefficient increment $\Delta K_{p}$ and integral coefficient increment $\Delta K_{i}$ are obtained through anti fuzzy, then there are

$$
\begin{aligned}
& K_{p}=K_{p 0}+\Delta K_{p} \\
& K_{i}=K_{i 0}+\Delta K_{i}
\end{aligned}
$$

where $K_{p 0}$ and $K_{i 0}$ are initial values of proportional coefficient $K_{p}$ and integral coefficient $K_{i}$ respectively. Collect solar panel voltage $V_{p v}$ and grid voltage $V_{\text {grid }}$ to compute feed-forward adjustment quantity $D$, and give the current passing zero compensation $\mathrm{Q}$, finally the duty cycle of PWM signal is calculated as $d=D+\Delta d+Q$ to drive the main circuit.

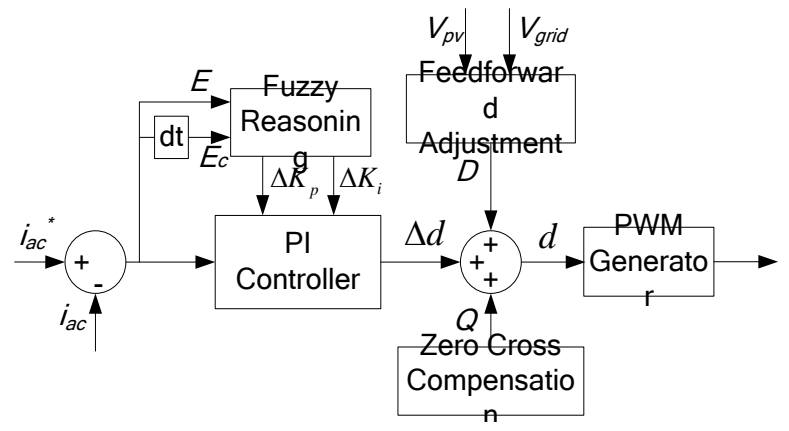

Figure 4 Current Control Strategy Block Diagram

\subsection{Optimization the Initial Parameters of PI Controller}

As the initial parameters of fuzzy PI controller, $K_{p 0}$ and $K_{i 0}$ have significant impact on the performance of the control system. It is known by Equation (12), $G(s)$ changes with the static working point $I_{m}, D$ and $V_{a c}$. Take further analysis, $D$ is mainly determined by the phase of $V_{g r i d}$, and $I_{a c}$ has the same phase with that of $V_{\text {grid }}$, so it is approximately that $D$ is determined by the phase of $I_{a c}$. Based on the approximate principle of the flyback converter, there is

$$
I_{m}=\frac{I_{a c} \cdot N}{1-D}
$$

That is, $I_{m}$ is determined by $I_{a c}$ and $D$. As a result, $G(s)$ changes mainly with the amplitude and phase of $I_{a c} . I_{a c}$ is sine wave, and its amplitude value varies dramatically from zero to peak during a quarter grid period. It is necessary to optimize the initial parameters of PI controller so that the controller is robust to the change of $I_{a c}$.

Assume the rated output power of PV module is $P$, grid voltage RMS is $V_{g r m}$, grid voltage phase is $\theta, I_{a c}$ RMS is $I_{r m s}$, and the peak value of $I_{r m s}$ is $I_{a c m a x}$, there is

$$
I_{a c m a x}=\frac{P}{V_{g r m}}
$$

In this paper, select $I_{r m s}=\left\{\frac{1}{3} I_{a c m a x}, \frac{2}{3} I_{a c m a x}, I_{a c m a x}\right\}$ and $\theta=\left\{30^{\circ}, 60^{\circ}, 90^{\circ}\right\}$ respectively, as a total of nine different static working points to perform the PI controller parameters optimization.

Genetic algorithm (GA) is a kind of randomized search method which simulate s the evolutionary mechanism. It has the virtues of parallel computing and global convergence, and is suitable for solving optimization problems $[15,16]$. So this paper 
takes the genetic algorithm to optimize the initial parameters of PI controller. The implementation steps are as follows:

1) Coding

Because GA could not directly process the data of solution space, it is necessary to encode them as genotype data of genetic space. 10 bits unsigned binary code is used respectively to express the two parameters $K_{p 0}$ and $K_{i 0}$, so the length of the genetic code is 20 bits.

2) Generation of initial population

First of all, estimate the scope of $K_{p 0}, K_{i 0}$ according to the experience. Then, the initial population is generated according to a uniform distribution within the scope, to ensure that the genetic algorithm could search for the optimal solution the in the whole feasible parameter range.

3) Calculate the individual fitness value

Fitness function is the objective function of optimization problem, its function is to calculate the fitness of individuals in the group, that is, to evaluate the performance of the individual. For the $i$ th static working point, $e_{i}(t)$ is the absolute error of the step response for $G(S)$. Choose the integral (ITAE) of the absolute error as evaluation index of the performance, then the fitness function is:

$$
J=-\sum_{i=1}^{9} \int_{0}^{\infty} t\left|e_{i}(t)\right| d t
$$

4) Genetic operation.

Perform selection, crossover and mutation operation, to produce new population.

5) Iteration

Calculate the fitness of the new population as step 3). If termination condition is met, it means the best parameters have been found. Otherwise, return to step 4) to continue the genetic operation process, until the termination condition is met.

Optimization of PI controller initial parameters is performed using Matlab genetic algorithm toolbox. The value range of $K_{p 0}$ is $[0,1]$, the value range of $K_{i 0}$ is $[0,5000]$, population size is 20 , roulette wheel model is adopted to perform the selection process, the crossover probability is 0.85 , the mutation probability is 0.01 , and optimization results are $K_{p 0}=0.012, K_{i 0}=860$.

Implement the closed-loop adjustment to the system using the optimized PI controller parameters, and the Bode plot is shown in Fig.5. The gain margin Gm is $15.6 \mathrm{~dB}$, and phase margin $\mathrm{Pm}$ is $81.2 \mathrm{deg}$. At the switching frequency $(57 \mathrm{kHz})$, ripple attenuation rate is $85.8 \mathrm{~dB}$. At the operating frequency $(100 \mathrm{~Hz})$, system gain is $9.38 \mathrm{~dB}$. Compared with the open-loop system, it is obviously that the adjustment has achieved sufficient stability margins, along with steady-state gain and switching frequency attenuation. 


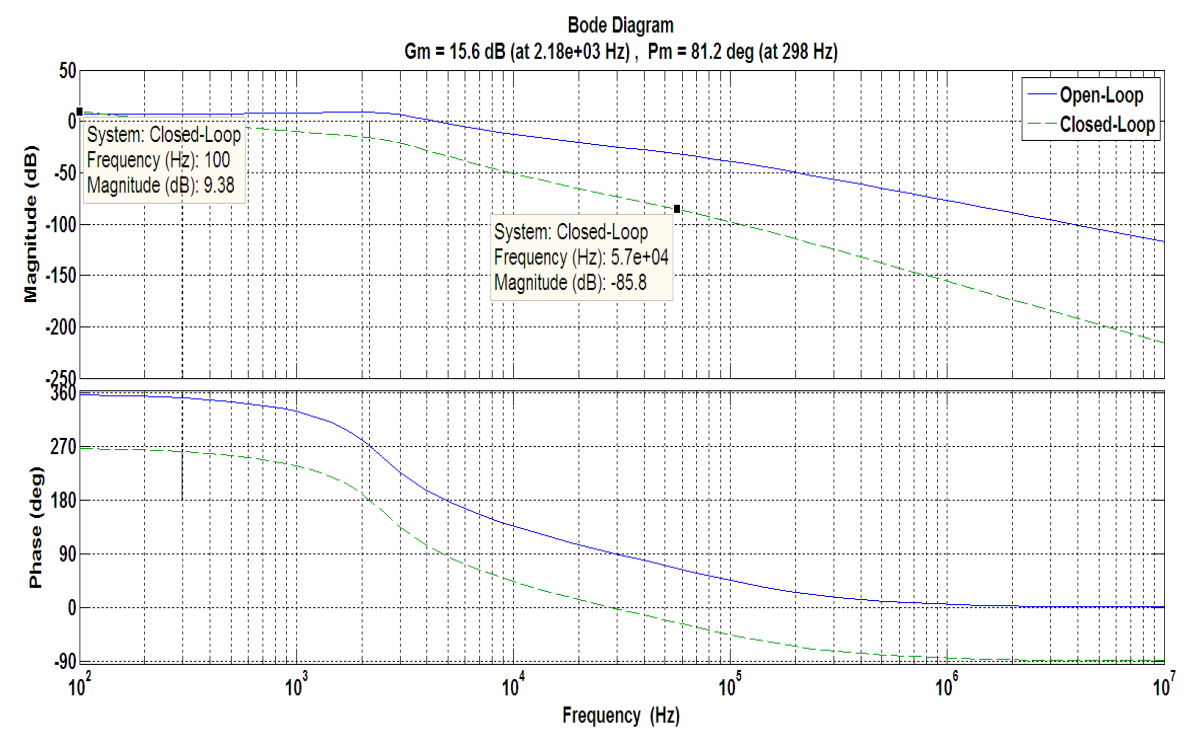

Figure 5 Bode Plot of the Closed-loop System

\subsection{Fuzzy Reasoning}

For fuzzy reasoning, take the grid-connected current deviation $E$ and its rate of change $E_{c}$ as input variables, the proportion coefficient increment $\Delta K_{p}$, integral coefficient increment $\Delta K_{i}$ as output variables. Fuzzy subset of the all the four variables are defined as $\{\mathrm{NB}, \mathrm{NM}, \mathrm{NS}, \mathrm{O}, \mathrm{PS}, \mathrm{PM}, \mathrm{PB}\}$. The universe of grid-connected current deviation $E$ is $[-0.15,0.15]$, the universe of grid-connected current deviation rate of change is $[-8500,8500]$, the universe of proportion coefficient increment $\Delta K_{p}$ is [0.005, 0.005], the universe of increment $\Delta K_{i}$ is [-100,100]. The membership function of Four variables of is shown in Fig. 6 respectively.

According to the knowledge of control theory and human control experience summary, in the design of adjustment rules to PI controller parameters, the following content should be considered:

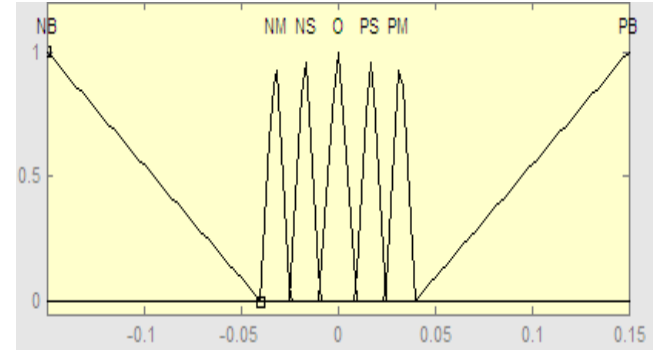

a) membership function of $E$

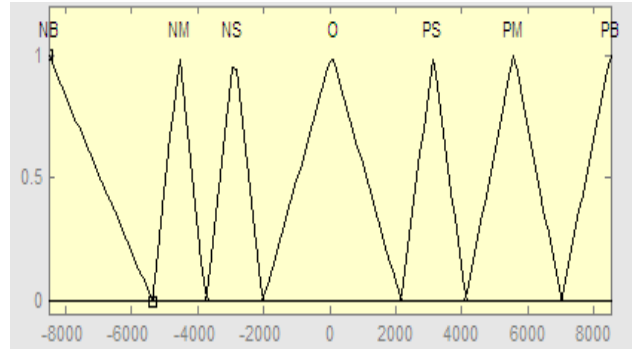

b) membership function of $E_{c}$ 


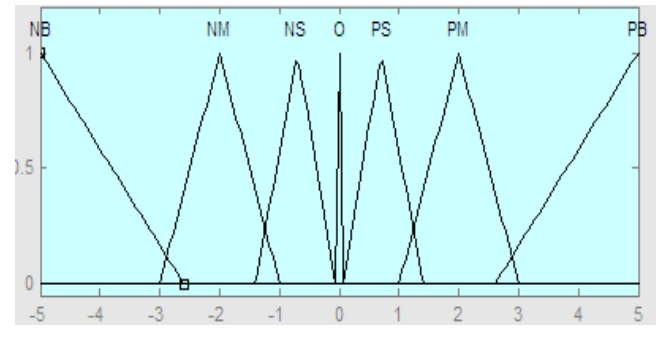

c) membership function of $\Delta K_{p}$

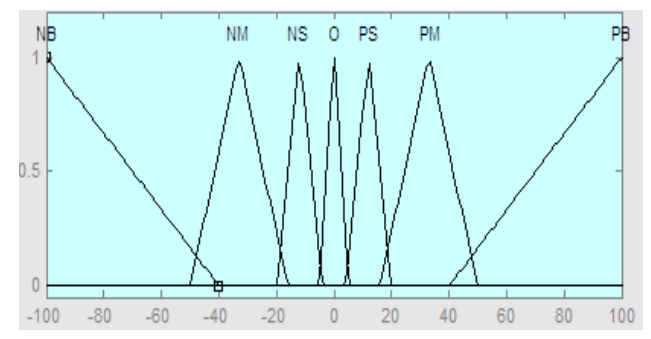

d) membership function of $\Delta K_{i}$

Figure 6. Membership Function of Input and Output Variables

1) when the deviation is big, in order to eliminate the deviation as soon as possible, $K_{p}$ should be given a great value, $K_{i}$ should be given a small value; when the deviation is small, in order to eliminate the deviation, prevent excessive overshoot and oscillation, $K_{p}$ should be given a small value, $K_{i}$ should be given a big value; when the deviation is quite small, in order to eliminate static error and prevent excessive overshoot, make the system stable as soon as possible, $K_{p}$ should be given the minimum values, $K_{i}$ should be given the maximum value.

2) When $E$ has the same sign with $E_{c}$, the regulated variable changes along the direction deviating from the set value; when $E$ has the opposite sign with $E_{c}$, the regulated variable changes along the direction converging toward the set value. Therefore, when $\mathrm{E}$ has the same sign with $E_{c}, K_{p}$ should be decreased, $K_{i}$ should be increased; when $E$ has the opposite sign with $E_{c}, K_{p}$ should be increased, $K_{i}$ should be decreased.

3) The greater the absolute value of $E_{c}$ is, the smaller the value of $K_{p}$ is, the greater the $K_{i}$ value is. On the contrary, the smaller the absolute value of $E_{c}$ is, the greater the value of $K_{p}$ is, the smaller the value of $K_{i}$ is.

Fuzzy rule tables are established according to the above rules, as shown in Tab.1 and Tab.2.

Table 1. Fuzzy Rules of $\Delta K p$.

\begin{tabular}{|c|c|c|c|c|c|c|c|c|}
\hline \multirow{2}{*}{$\Delta K_{p}$} & \multicolumn{7}{|c|}{$E_{c}$} \\
\cline { 2 - 9 } & NB & NM & NS & O & PS & PM & PB \\
\hline & PB & O & PM & PM & PB & PB & PB & PB \\
\hline & PM & O & PS & PS & PM & PM & PM & PB \\
\hline & PS & PS & O & O & PS & PS & PM & PM \\
\hline & O & PS & PS & O & O & O & PS & PS \\
\hline & NS & PM & PM & PS & PS & O & O & PS \\
\hline & NM & PB & PM & PM & PM & PS & PS & O \\
\cline { 2 - 8 } & NB & PB & PB & PB & PB & PM & PM & O \\
\hline
\end{tabular}

Table 2. Fuzzy rules of $\Delta K i$.

\begin{tabular}{|c|c|c|c|c|c|c|c|c|}
\hline \multirow{2}{*}{$\Delta K_{i}$} & \multicolumn{7}{|c|}{$E_{c}$} \\
\cline { 2 - 9 } & NB & NM & NS & O & PS & PM & PB \\
\hline \multirow{2yyyyyyyy}{*}{$E$} & PB & PS & PS & PS & PM & PS & PS & O \\
\cline { 2 - 8 } & PM & PM & PM & PM & PM & PM & PS & PS \\
\cline { 2 - 8 } & PS & PB & PM & PM & PB & PB & PM & PM \\
\hline & O & PB & PB & PB & PB & PB & PB & PB \\
\cline { 2 - 9 } & NS & PM & PM & PB & PB & PM & PM & PB \\
\cline { 2 - 9 } & NM & PS & PS & PM & PM & PM & PM & PM \\
\cline { 2 - 9 } & NB & O & PS & PS & PS & PS & PS & PS \\
\hline
\end{tabular}


Fuzzy operation adopts single-point fuzzy method, AND operation adopts minimum calculation rule, implication operation adopts Mamdani-minimum calculation rule, synthetic operation adopts the maximum-minimum calculation rule, and clearness operation adopts center of gravity method(COG).

\subsection{Grid Voltage Feed-forward and Current Zero Compensation}

In order to improve the dynamic response speed of system, the grid voltage $V_{\text {grid }}$ is introduced to perform feed forward adjustment. Feed forward compensation $D$ is the steady-state value of duty cycle, and could be calculated according to the relations between input voltage $V_{p v}$ and output voltage $V_{a c}$ of the flyback converter

$$
V_{a c}=\frac{N \cdot D}{1-D} V_{p v}
$$

Then

$$
D=\frac{V_{a c}}{V_{a c}+N \cdot V_{p v}}
$$

Because $R_{f} 、 L_{f}$ is quite small, $V_{a c} \approx V_{\text {grid }}$, there is

$$
D=\frac{V_{g r i d}}{V_{g r i d}+N \cdot V_{p v}}
$$

At the time of grid-connected current crossing zero, the change rate of the set value is maximum, and the biggest control deviation is appeared usually, as a result, it is easy for integral saturation to occur, which will cause oscillation in current commutation, and the harmonic content is very big in a period of time after the crossing zero. In order to solve this problem, certain compensation quantity $Q$ is given to the output of PI controller at the current passing zero point, which will prevent the integral saturation, and improve the response speed of system.

\section{Simulation of micro-inverter system}

Simulation model of the system is established using the Matlab SimElectronics component library. According to the result of genetic algorithm optimization, the initial value of the fuzzy PI controller parameters are $K_{p 0}=0.012, K_{i 0}=860$. Set compensation quantity of grid-connected current crossing zero $Q=0.008$, and simulation structure of the micro-inverter system is shown in Figure 7.

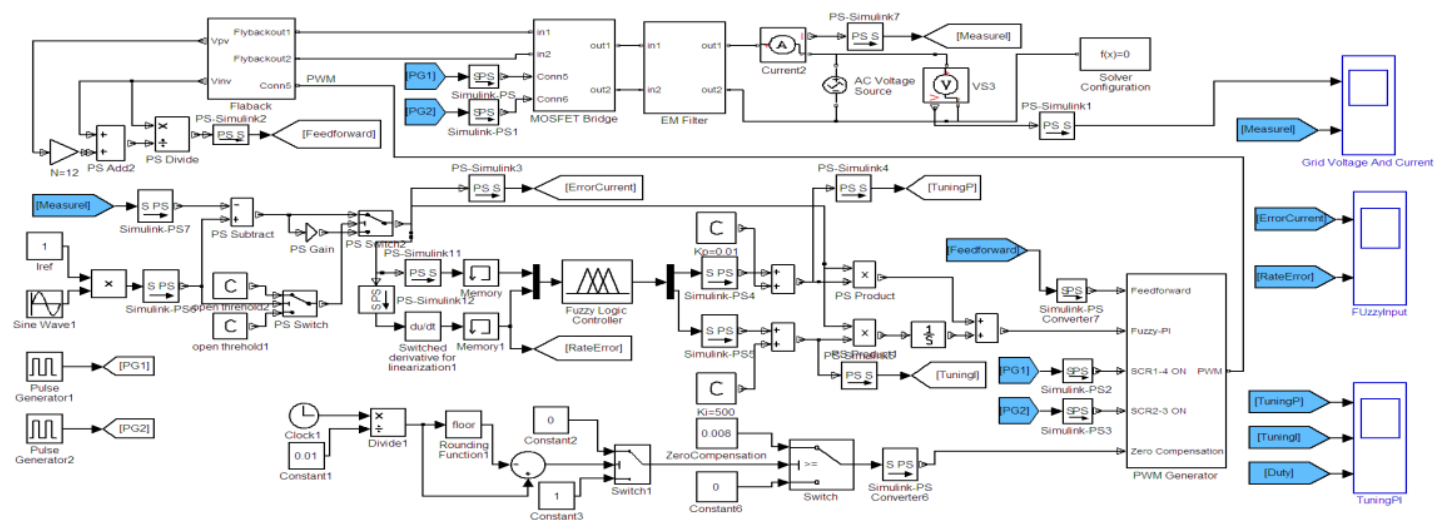

Figure 7. Simulation of Micro-inverter System 
Assign the RMS of reference current $i_{a c}{ }^{*}$ as $0.7 \mathrm{~A}(70 \%$ Rated power), control method of fixed parameter PI controller combined with feed forward compensation and control method of fuzzy PI controller combined with feed forward compensation are performed respectively. Grid-connected current waveforms and the deviations of the two methods are shown in Figure 8 and Figure 9. Obviously, compared with the gridconnected current obtained by fixed parameter PI controller, the grid-connected current obtained by fuzzy PI controller has higher sine degree and less deviation.

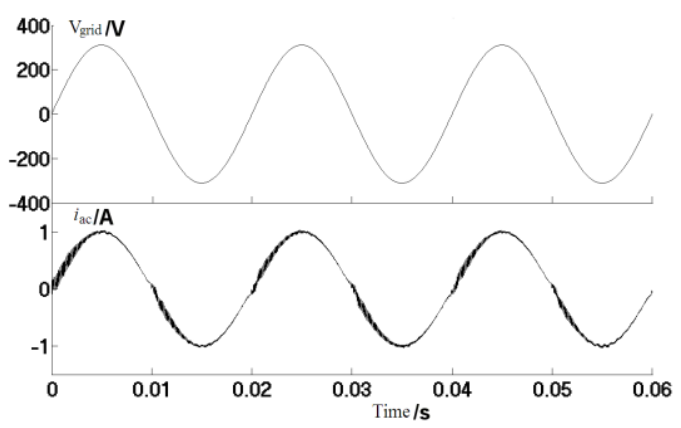

1) Waveform of grid-connected current

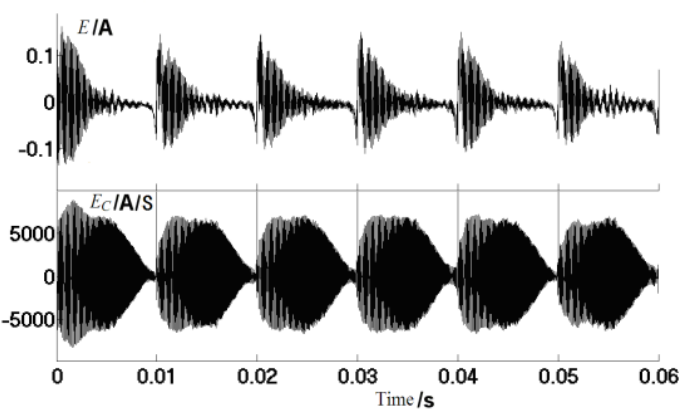

2) Grid-connected current deviation

Figure 8. Simulation for Control Method of Fixed Parameter PI Controller Combined With Feed Forward Compensation.

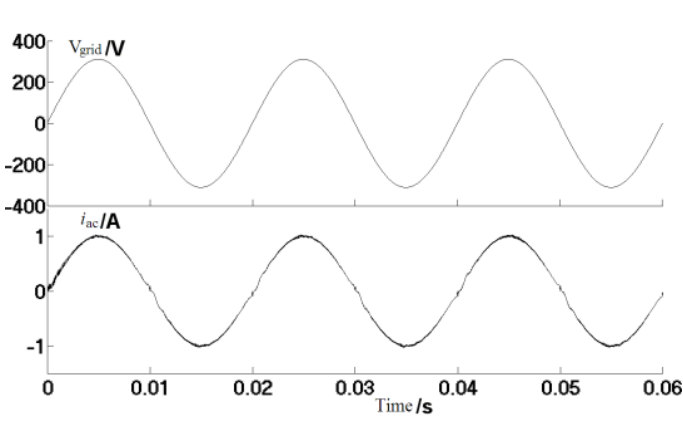

1) Waveform of grid-connected current

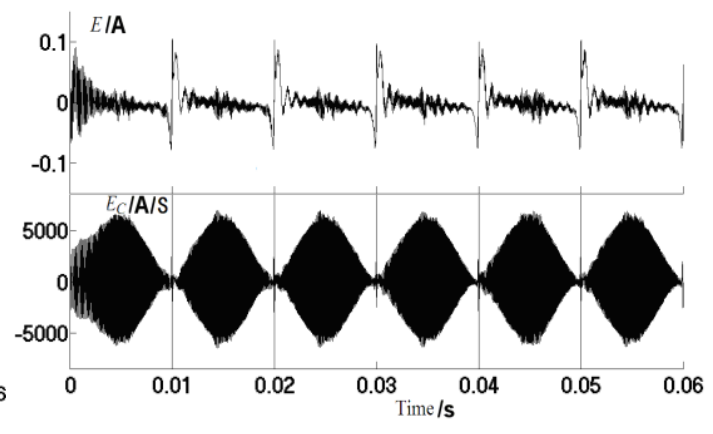

2) Grid-connected current deviation

\section{Figure 9. Simulation for Control Method of Fuzzy PI Controller Combined With Feed Forward Compensation.}

In order to compare the power quality of the two methods, FFT analysis of the gridconnected current is implemented, as shown in Fig.10. Harmonic content of gridconnected current that obtained by fixed parameter PI controller is $5.56 \%$, and obtained by fuzzy PI controller is $2.21 \%$, which shows that the fuzzy PI controller could effectively improve the quality of grid-connected current. 


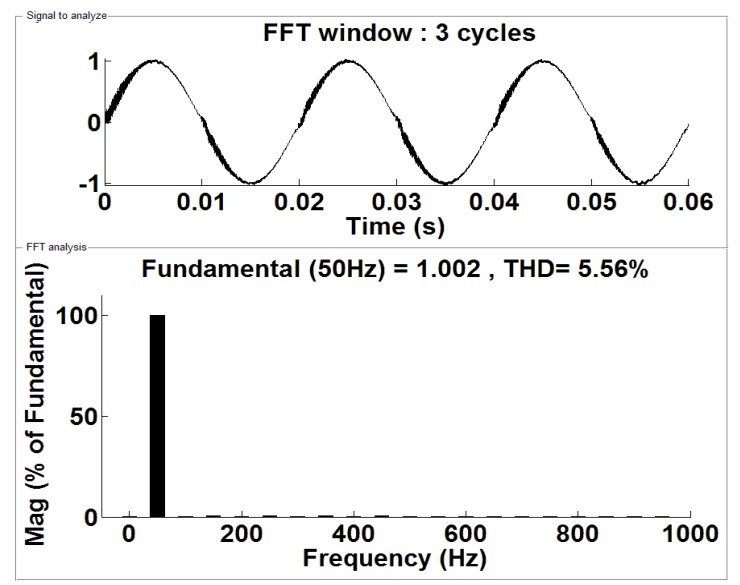

1) Fixed parameter PI controller

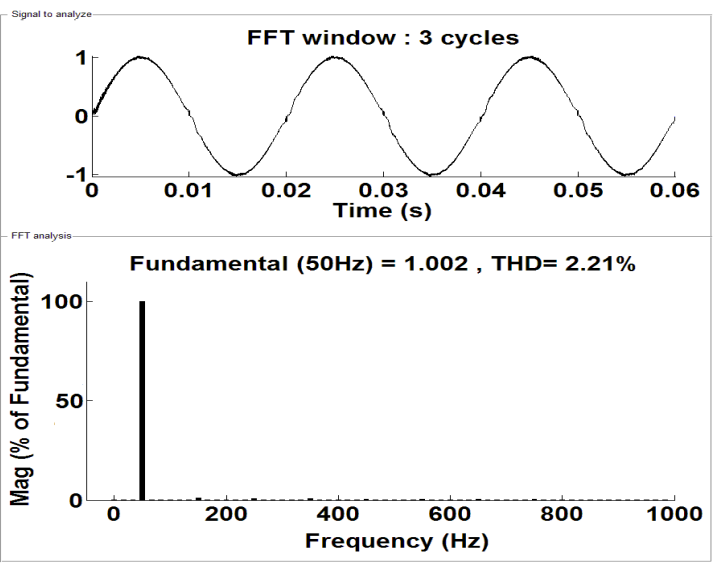

2) Fuzzy PI controller

\section{Figure 10. FFT Analysis of the Grid-connected Current}

Compare the grid-connected current harmonic content of the two methods under the working conditions at $20 \%, 40 \%, 60 \%$ and $100 \%$ of rated power respectively, as shown in Tab.3. It is known that fuzzy PI controller has good robustness to the change of working conditions, the harmonic content of grid-connected current is less than that of fixed parameter PI controller, and conform to the state power grid harmonic content standard (THD $<5 \%)$.

\section{Table 3 Harmonic Content Comparison of Two Methods Under Different Working Conditions}

\begin{tabular}{cccc}
\hline Order & Power & $\begin{array}{l}\text { Harmonic content of fixed } \\
\text { parameter PI controller }\end{array}$ & $\begin{array}{l}\text { Harmonic content of fuzzy PI } \\
\text { controller }\end{array}$ \\
\hline 1 & $20 \%$ & $9.52 \%$ & $3.24 \%$ \\
2 & $40 \%$ & $10.4 \%$ & $3.36 \%$ \\
3 & $60 \%$ & $7.85 \%$ & $2.95 \%$ \\
4 & $100 \%$ & $6.68 \%$ & $2.77 \%$ \\
\hline
\end{tabular}




\section{Conclusion}

Grid-connected solar micro-inverter could solve the problems of unsafety, low efficiency in centralized inverter. As a high nonlinear and time-varying system, it is difficult to achieve good control effect using traditional PI controller. In this paper, small signal analysis model of micro-inverter is established, grid-connected current control strategy composed of fuzzy PI controller and grid voltage feed-forward is put forward. Simulation results show that the control strategy has the virtues of good robustness, small dynamic deviation, and could reduce the harmonic content of grid-connected current.

\section{Acknowledgements}

The work of this paper is supported by "the Fundamental Research Funds for the Central Universities” of North China Electric Power University.

\section{References}

[1] Z. Zai-teng, C. Xiao-fang and D. Jin-lei, et al., "Characteristics of partially shadowed serial PV module output”, Journal of University of Science and Technology of China, vol. 39, (2009), pp. 398-402.

[2] L. Guo-liang, L. Ming, and W. Liu-ling, et al., "Analysis of Output Characteristics of Super Cells Serial Module with Partial Shading”, Acta Optica Sinica, vol. 31, (2011), pp. 236-241.

[3] W. Bower, R. West and A. Dickerson, "Innovative PV Micro-Inverter Topology Eliminates Electrolytic Capacitors for Longer Lifetime", Photovoltaic Energy Conversion, Conference Record of the 2006 IEEE 4th World Conference on, vol. 2, (2006), pp. 2038-2041.

[4] M. Joshi, E. Shoubaki, R. Amarin, B. Modick and J. Enslin, "A high-efficiency resonant solar microinverter", Power Electronics and Applications (EPE 2011), Proceedings of the 2011-14th European Conference on , (2011), pp. 1-10.

[5] A. C. Kyritsis, E. C. Tatakis and N. P. Papanikolaou, "Optimum design of the current-source flyback inverter for decentralized grid-connected photovoltaic systems", IEEE Transactions on Energy Conversion, vol. 23, (2008), pp. 281-293.

[6] G. Wen-xiang, W. Ming-yu and W. Li-jian, et al., "Review of research on photovoltaic micro-inverter", Power System Protection and Control, vol. 40, (2012), pp. 147-155.

[7] Z. Yue, H. Xiao-fei, Z. Zhi-liang and L. Yan-fei, "A hybrid control method for photovoltaic grid-connected interleaved flyback micro-inverter to achieve high efficiency in wide load range", Applied Power Electronics Conference and Exposition (APEC), 2013 Twenty-Eighth Annual IEEE , (2012), pp.751-756.

[8] G. Wen-xiang, W. Ming-yu and L. Yang, et al., "Research on Flyback-Type Photovoltaic Micro-Inverter", Low Voltage Apparatus, (2012), pp. 23-28.

[9] Z. Feng-ge, Z. Shi-lu and Y. Xiao-ju, et al., "Controller Design of Grid-Connected Micro inverter Based on Interleaved Flyback Structure", Transactions of China Electrotechnical Society, vol. 28, (2013), pp.142$147+153$.

[10] Z. Jie and H. Xue-long, "Research on micro-inverter for grid-connected photovoltaic system", Electronic Measurement Technology, vol. 36, (2013), pp. 1-8.

[11] C. Fu-lai and Z. Xiao-guang, "Research on a New Type of Photovoltaic Micro-Inverter System", Electrotechnics Electric, no. 2, (2013), pp. 10-12+39.

[12] http ://ww1.microchip.com/downloads/en/AppNotes/01444A.pdf

[13] S. Hai-shun, M. Fan and L. Li-ming, et al., "An UPFC Fuzzy PI Self-Tuning Control Strategy", Transactions of China Electrotechnical Society, no. 9, (2007), pp. 136-142.

[14] C. Wei, X. Dan and W. Hui-min, et al., "Fuzzy PI Controller For No-Load Cutting-In Control of Doubly Fed Induction Generator in Wind Power System”, Acta Energiae Solaris Sinica, no.6, (2009), pp, 794-798.

[15] M. J. Neath, A. Swain and U. Madawala, et al., "An Optimal PID Controller for a Bidirectional Inductive Power Transfer System Using Multi-objective Genetic Algorithm”, IEEE Transactions on Power Electronics, vol. 99, (2013), pp. 1-10.

[16] M. R. Rani, H. Selamat and H. Zamzuri, et al., "PID controller optimization for a rotational inverted pendulum using genetic algorithm", 2011 4th International Conference on Modeling, Simulation and Applied Optimization, (2011), pp.1-6. 


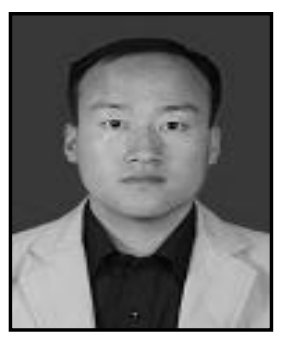

Weiliang Liu received the B.S. degree in Automation from North China Electric Power University (NCEPU), Baoding, China, in 2005, and the M.S. degree in system engineering from Xi'an Jiaotong University (XJTU), Xi'an, China, in 2008, respectively. He is currently a Lecturer with the Department of Automation, NCEPU. Meanwhile, he is a PhD candidate in control theory and control engineering in NCEPU. His research interest is control technology in new energy generation and micro-grid.

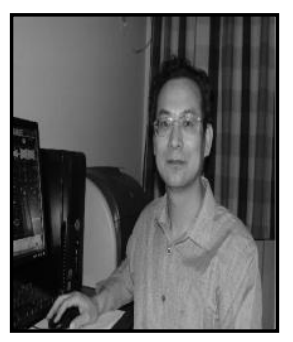

Changliang Liu received the B.S. degree in thermal power engineering, the M.S. and Ph.D. degrees from North China Electric Power University (NCEPU), Baoding, China, in 1985, 1990, and 2002, respectively. He is currently a Professor with the Department of Automation, School of Control Science and Engineering, NCEPU. His research interests include modeling of power plant and simulation of new energy generation.

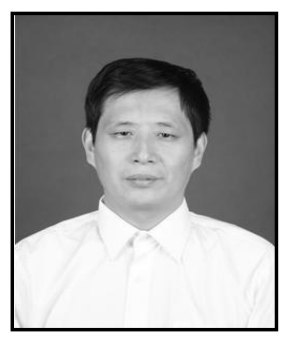

Yongjun Lin received the B.S. and M.S. degrees in measurement and automation, and the $\mathrm{Ph} . \mathrm{D}$. degree in thermal power engineering from North China Electric Power University (NCEPU), Baoding, China, in 1986, 1989, and 2002, respectively. He is currently a Professor with the Department of Automation, NCEPU. His research interests include application of embedded technology and control technology in microgrid.

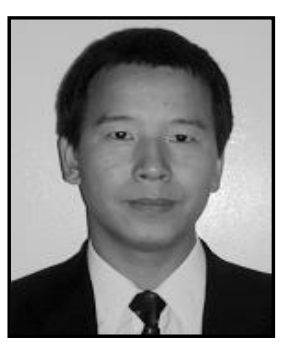

Liangyu Ma received the B.S. degree in thermal power engineering, the M.S. and Ph.D. degrees from North China Electric Power University (NCEPU), Baoding, China, in 1993, 1996, and 2004, respectively. From March 2008 to February 2009, he was a Visiting Scholar at Baylor University, Waco, TX. He is currently an Associate Professor with the Department of Automation, NCEPU. His research interests include power plant modeling and simulation, condition monitoring and intelligent fault diagnosis for power station thermal facilities and systems, and intelligent control and application to power plants. 
International Journal of Control and Automation Vol.7, No.10 (2014) 